\title{
Investigate the Most Important Causes of Job Burnout of Employees (Case Study: Youth and Sports General Directorate of Qom)
}

\author{
RAD Raheleh Tayyebi ${ }^{37}$, JAMSHIDI Mina ${ }^{38}$
}

\begin{abstract}
Human resources of any organization are precious resource of that organization that can assist it in achieving its goals. Specialist staff, loyal, consistent with the values and organizational objectives have strong motivation and willing and committed to maintain and continue organizational membership are basic and essential needs of any organization. Hence, we decided to take a step in in this important by providing this work; This study have been developed in descriptive analytical method with aim of fulfilling to create communication between the components and characteristics of job burnout of some of department of sport and youth personnel of Qom, using a standardized questionnaire SPSS software. The population of this study consisted of 230 personnel of the General Directorate of Youth and Sports of Qom on two levels of employees and the President and the results indicate that existence of job features including variety of tasks, conscientiousness, the nature of the task, independence and feedback on job have significant impact on reducing burnout syndrome of employees.
\end{abstract}

Keywords: human resources, organizational goals, job burnout, Qom

JEL: 015

UDK: 159.944.4.072

613.86

COBISS.SR-ID 253518860

\section{Introduction}

In today's competitive world, organizations are constantly seeking new ways to maximize employee performance and efforts. Changing and dominant conditions on organizations, increasing competition and the need for effectiveness in such circumstances, reveal their need for the valuable generation of staff, generation that are called as (organizational veterans).

One of the factors affecting decrease in performance and effectiveness of human resources in organizations, is the phenomenon of job burnout. It seems that job burnout be associated with psychological pressures. psychological pressures occur when there is an imbalance between environmental demands and individual's ability to respond them. Whatever the environmental demands increase and individual's ability to respond them decrease the psychological pressures is created which causes negative experience in individual and job burnout. In fact, job burnout occurs as a result of constant psychological pressure (Farber 1983). Job burnout is also caused a deterioration in the quality of service provided by the staff (Saatchi, 1382).

${ }^{37}$ Islamic Azad University, Tehran, Iran

${ }^{38}$ Islamic Azad University, Tehran, Iran 


\section{Problem statement}

Job burnout is a professional risk that is associated with reduction in employees' physical and mental energy. Nowadays job burnout has attracted much attention by researchers and corporate leaders that mainly is associated with important individual and organizational outcomes such as job performance, organizational behavior, job attitudes and negative psychological consequences (Martinkou, 2004). Job burnout has negative impact on employees, family, friends and those around them and in general has a negative impact on society, and can reduce quality of life for employees both at work and in their home. Over time, job burnout can lead to increased problems at home and also the withdrawal from family and friends. Job burnout is a painful experience for individuals and a costly phenomenon for organizations.

Costs of job burnout for employees and their families is also very heavy which includes direct costs such as lack of membership and participation of employees, absenteeism, turnover, strikes, reduced job performance, reducing the quality and quantity of output and job accident and indirect costs such as loss of vitality, job dissatisfaction, low commitment, reducing the quality of relationships, distrust, hostility and aggression. Hence biggest concern of researchers is to investigate the causes and control of this important which will be discussed in the following.

\section{Job characteristics}

The prelude to job characteristics attitude was Turner and Lawrence studies. They put a major project into action to assess the staff react to different jobs. They believed that employees prefer complex and working jobs to monotonous and uninteresting jobs and believe that will be followed by complexity of the job, satisfaction and the presence of employees (Moorhead, Griffin, 1382). Job characteristics refers to activities, tasks, assignments and various aspects of a job. Some of the jobs, are conventional and ongoing because their activities are homogeneous and repeated and some other are unusual; Some require different skills and some other limited practical field; Some tires employees by making theme to strict compliance of trends and some other gives employees the freedom to do their work willingly. Some jobs are most successful when are done collectively by a group of employees and some other are done by people who are essentially independent and work (Keshtidar, 2002).

\section{Job characteristics theory}

There are at least seven theories on the characteristics of job. Fortunately, they have a lot in common. For example, hygiene motivation theory of Herzberg's and research was conducted on the need for achievement by McClelland are both among the job characteristics theories.

Herzberg suggests that if the job can lead to success, reputation, responsibility and such things, will cause an increase in job satisfaction of workers or employees. McClelland proved that those who achieved more opportunities will have great performance and will accept great responsibility (Parsaeian, Arabi, 1386).

Here we will point three job characteristics theories:

1. Attribution theory of job

2. Social information processing model

3. Job Characteristics Model

\section{Job burnout and its creation}

To address the issue of job burnout and express opinions on the issue should first define two terms of "job strain and psychological stress".

Job strain and psychological stress are two words often used interchangeably, but do not have the same meaning. Job strain is necessary for advancement in life. But if go beyond the 
necessary limit leads the psychological stress. Psychological stress does not lead to advancement. Neumann and Pierre defined job strain as: a condition that arises in the effect of employment situation and distract individual from the usual action. Inavcevich and Matteson believe that job strain is an adaptive response that is realized by personal characteristics or psychological processes. So, can be said that Psychological stress, is his reaction against the wrong amount of pressure (Moshabbaki, 1376).

\section{Job Burnout}

\section{What is Job Burnout?}

The term burnout been applied by Herbert J. Freudenberger for the first time in the year $1974 \mathrm{AD}$ to describe a particular kind of job burnout. He used this term to explain the progressive states of emotional discharge, loss of motivation and decreased commitment among young volunteer employees who worked with commitment in a medical clinic. In 1976, Maslach after a long time listening to issues of social service employees mentioned the phenomenon of indifference and neglect feel about the client's (Zarei Matin, Anvari, 1391). But in the years 80's and 90's this disorder was recognized as a distinct disorder and also separate strategies must be recommended to fix it. Job burnout is used to describe a syndrome that mainly affects people working in social sanitary centers. Such as lawyers, managers, doctors, counselors, teachers and people who are active in law enforcement, considered jobs have particular respect in the society and are dealing with patients that have important needs and are suffering difficult conditions. In these jobs, change and interaction is high and there is a direct and continuous and repetitive relationship with clients. So, considered syndrome in professions that provide help, appears more in profession helping, however, burnout is not specific to these professions and also is seen in other professions. The term burnout is used among several Persian equivalents that are proposed for Burnout. Among other proposed equivalents can be mentioned exhausted, power failure, stroke work, burnout, job fall, detachment, job exhaustion and mental erosion (Asgari, 1383). Nowadays job burnout has attracted great attention by researchers and corporate leaders that mainly is associated with important individual and organizational outcomes such as job performance, organizational behavior, job attitudes and negative psychological consequences.

\section{Stages of job burnout}

Four stages of job burnout include:

- Honeymoon State

- Fuel Shortage State

- Chronic Symptom State

- Crisis state

- Hit the wall state

\section{The causes of job burnout}

Individual factors

Organizational Factors

Environmental factors

Social factors

Job factors 


Permanent Pressure
- Sense of danger
- The relentless competition
- Extreme specialization
- Tension and conflict in the
workplace
- Private problems
(especially financial
implications)
- IIIness
- Hatred of jobs
- Lack of human
communication in the
workplace
- The unknown future
- Loneliness
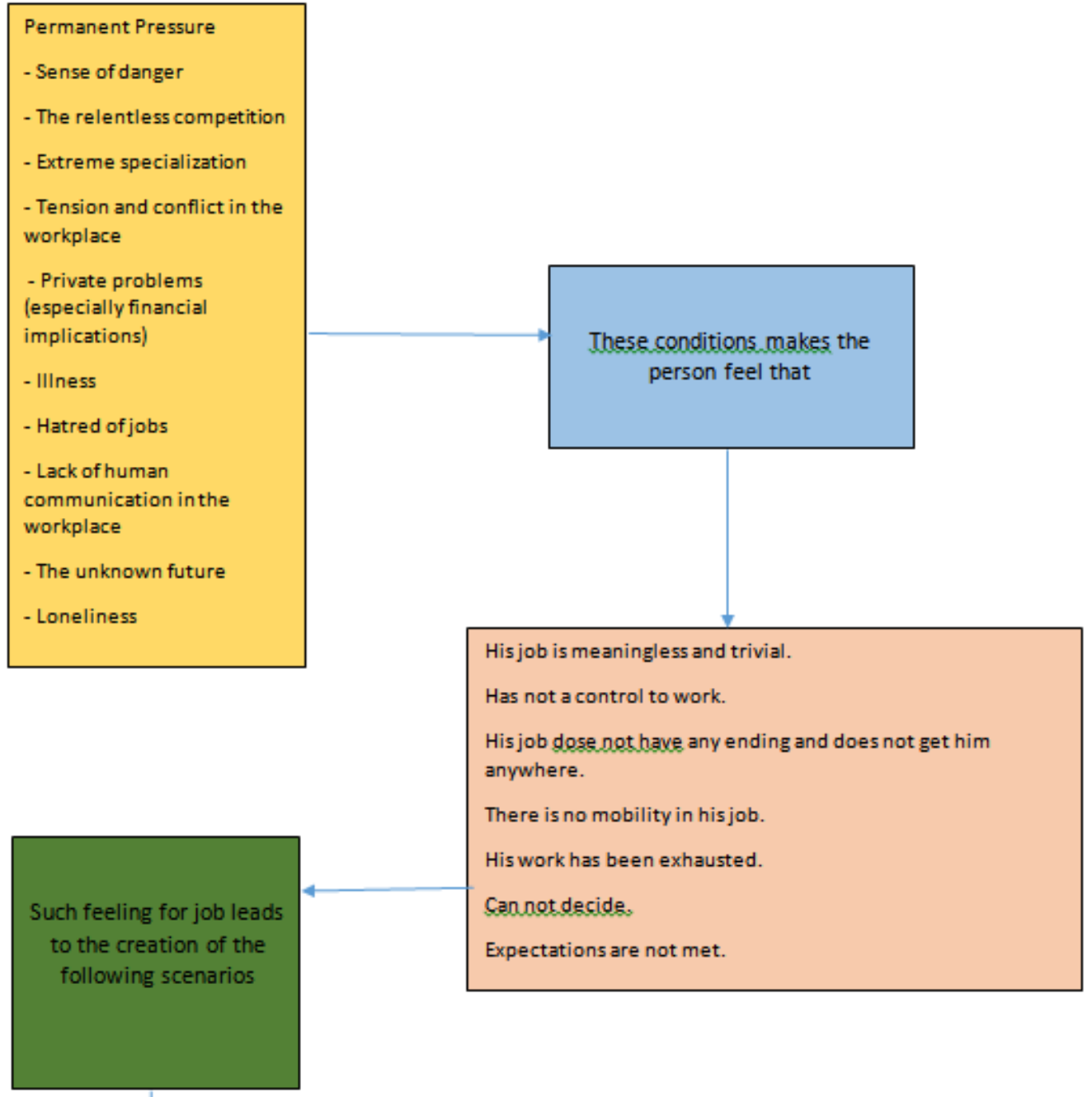

His job is meaningless and trivial.

Has not a control to work.

His job dose not have any ending and does not get him anywhere.

There is no mobility in his job.

His work has been exhausted.

Cannot decide.

Expectations are not met.

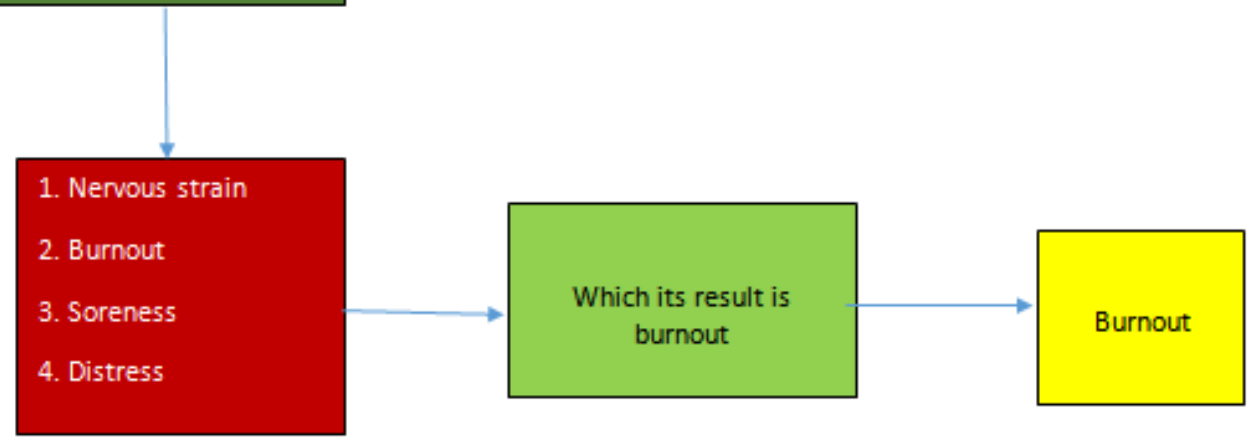

Fig. 1. Circumstances establishing job burnout in staff

\section{The signs of job burnout}

Person who has job burnout his self-respect descends, his personal relationships disappears, he may feel that too much works and is not able to control his much work. He knows himself as a swimmer against the water moves and is unable to keep his head above water. This condition causes a person's sense of hopelessness and helplessness. Job burnout happens periodically and 
it is essential that we come to accept such a period and is easily treatable if recognized at an early stage. But the first step in dealing with this case is being aware of its symptoms (Geldard, 1374).

The first stage of Job burnout, is physical burnout. This type of burnout, is one of the constituents of the disability. A person who is exhausted, complains about extreme boredom (often associated with insomnia). In addition, the person usually experiences signs indicating lack of energy, chronic fatigue and also weakness.

The second aspect of job burnout, is emotional burnout. When person's physical reserves are finished due to continued stressful job conditions, it may be parallel to that person's emotional force, ends. Worker or employee who has lost his power and is exhausted, expresses feelings such as depression, helplessness and frustration by itself. In these conditions, satisfaction that acquired before and at the time of leisure or beside family and friends' decreases and as a result, the overall satisfaction with life decreases.

The third aspect of job burnout, is mental burnout. In this case, the worker deal with the negative view towards work, customers or client of the organization and colleagues. The fact that such a person is exhausted and is not able to observe the feelings and needs of others, in fact, indicate that his dealing is free of humanitarian aspects. These negative attitudes and inhuman attitude may extend to family environment and friendly circles of the person with job burnout (Saatchi, 1387). L-Moss (1981) in his efforts to classify effects and results of job burnout, has classified these effects into three categories of physical indicators, behavioral changes and job performance.

\title{
Warning signs of job burnout
}

\author{
Feeling of emptiness \\ Negative feelings and emotions \\ Loss of motivation \\ Depression \\ Drug abuse \\ Vicious cycle \\ Emotional withdrawal \\ Decreased performance \\ Reduced levels of physical health \\ Interpersonal problems \\ Despair and frustration
}

\section{Confronting strategies with job burnout}

Coping strategies with job burnout can generally be classified in two categories, namely, individual strategies and organizational strategies.

\section{Organizational strategies to cope with job burnout}

Employ people who in addition to being interested to a particular job, also have necessary personality traits to fulfill the duties of the job.

Holding training courses appropriate to operators of various occupations.

Reduce using either methods reprimand and punishment.

Reduce dangerous conditions in the organization.

Improving communication networks and interaction in the organization.

Identify stressors in the organization and try to eliminate those factors.

Provide the most suitable conditions for the growth of the abilities and talents of employees. 
Identify workers, employees, professionals and especially managers who have a moderate or severe behavioral disorders or psychological distress, and the help of Psychiatry and Clinical Psychology to treat them.

Providing health care services to help regain mental health of employees and restoring their psychological competence.

Design and implementation of effective education programs in the field of mental health in the work environment (Saatchi, 1390).

\section{Materials and Methods}

At the stage data analysis, the researchers are forced to use statistical methods to identify the characteristics of the studied phenomenon or relationships of phenomena and variables and calculate and estimate required indicators to for a researcher to identify the status of variables in the sample and to find the necessary knowledge. Also, to study the relationship between variables, the researcher has to use inferential statistical methods.

For this reason, demographic variables were studied at first. To test the normality of the population we used K-S test and then addition to multivariate test (t-test) then investigated the status of research variables and using confirmatory factor analysis research variables construct validity was confirmed over two times. Finally, using structural equation modeling investigated research hypotheses. According to the results of the structural equation, a significant positive impact on job characteristics and its components on the lack of job burnout and all research hypotheses were confirmed. Also, should be noted that no significant difference was observed between these two components.

\section{Conclusion}

Our world is organizations world and the main driver of this wheel is humans. The ones who give life to the organization will permit the realization of goals. Without human the organization is meaningless and management is an imaginary (Griffin, 1382). Human resources are as the main and the largest and most valuable asset of an organization, community and country, so because of that countries and organizations has long invested on this valuable force and try to fertilize it and societies reach progress, prosperity and excellence which can thrive these forces and talents behind them (Nasrollahpour, 1385). Humans by undertaking the organizational tasks are reviving the organization, of course, each of the tasks and jobs in the the organization has its own specific characteristics. Attitude of job characteristics in job design was superior attitude in the 1970s and early 1980s. This attitude that was concluded from studies on job motivation characteristics (such as autonomy and feedback) have an evolved form that explicitly considered status of individual differences in response of employees to a job and finally become as job characteristics theories (Griffin, 1382).

However, nowadays, the emergence of threatening areas of human resources in different organizations are known as one of inevitable defects in organizational efficiency. One factor that reduces the efficiency of precious human capital, is the phenomenon of job burnout.

Destructive effects of this phenomenon on individual and social life is evident and educational organizations staff are considered as one of the most vulnerable segments of society against job burnout. Psychological, occupational stress and its consequences are one of the most critical issues of work life in today's industrial complex world. Job pressures on organizational forces have large costs for the organization and may be harmful and malignant and have serious effects sought and undermine the mobility and attempts of human and cause lack of efficiencies and productivity and efficient use of resources and finally effectiveness of the organizations.

Nowadays because of the dramatic changes that job burnout can leave on the quality of personal, family and professional life of a person is considered as a serious problem. 
Suggestions

1. Job Characteristics model of Oldham and Hackman focuses on jobs and does not pay attention employment and since in this study considered job characteristics model is Oldham and Hackman's model, thus employee's personality and his personal characteristics is not considered, however in the real world there is no job without employee and in addition to job characteristics employee's characteristics and personality should be considered. So, we hope that these factors be seen in further research and employee's features be added to job characteristics, and these two factors be considered together.

2. Researchers can implement the same issue in other organizations or other production and service centers and comparatively compare the results.

3. Other researchers can simultaneously implement this issue in the public and private sectors and compare obtained results with each other.

4. Researchers can examine relationship between work factors (based on job characteristics) with productivity, efficiency, quality of performance, effectiveness, motivation, absenteeism and staff turnover.

\section{REFERENCES}

1. Abzaari, M., Seraydaryan, H. (1376). Management and Psychological stress, Isfahan, Arkan publications.

2. Alwani, M. (1386). Public administration, Tehran, Ney publication.

3. Blood. M.R., Hultin. C. L (1967). "Alienation Environmental Characteristic and Worker Response". Journal of Applied Psychology. 51. 284-290.

4. Cooper, C. L., Dewe., P. J., O’Driscoll, M.P. (2001). "Organizational stress: a review and critique of theory, research, andapplications". Sage publications. Inc.

5. Dehghan Marvast, A. (1378). analyze the relationship between occupational factors with organizational committing based on job characteristics, Tehran's Allameh Tabatabai University, Master's thesis of Management.

6. Farber, B. A. (1983). "Stress and Burnout in The Human Service Professions". New York: Pergamon Press.

7. Fedai, M., Yeter, D. (2010). "The Impacts of Structural and Psychological Empowerment on Burnout: A Research on Staff Nurses in Turkish State Hospitals", Canadian Social Science, Vol. 6, No. 4, pp. 63-72.

8. Freudenberger, H. J. (1974). "Staff Burnout". Journal of Social Issues, Vol. 30, pp. 159-65.

9. Freudenberger, H. J. (1975). "The Staff Burn-Out Syndrome in Alternative Institutions", Psychoterapy: Theory, Research and Practice. 12 (1), 73-82.

10. Garg, P., Rastogi, R. (2006). "New Model of Job Design: Motivating Employees'performance", Journal of Management Development, Vol. 25, pp. 572-587.

11. Hackman, J. R., Lawler, E. E. (1971). "Employee Reactions to Jobcharacteristics". J. of Applied Psychology 55: 259.286.

12. Hackman, J. R., Oldham, G. R. (1976). "Motivation Through the Design of Work: Test of A Theory". Organizational Behavior Andhuman Performance, 250-279.

13. Hackman, J.R., Oldham, R.G. (1980). "Work Redesign", Reading, Ma: Adisson - Wesley

14. Hackman, J.R., Oldham, R.G. (1975). "Development of The Job Diagnosticsurve", Journal Applied Psychology, Vol. 60 (2), pp. 159-170.

15. Jeldkar, M. (1379). Compare the psychiatric and non-psychiatric nurses job burnout in Noor, Farabi medical centers and Modarres rehabilitation, Khuzestan: Islamic Azad University psychology master's thesis.

16. Keshtidar, M. (2002). "A Study of the Relationship Between Source of Control a Stress and Compare Between Faculty Managers and Sporting Groups and Non- Sporting Group", Ph.D. Dissertation, Tehran University, Tehran, Iran. (In Pesian).

17. Khairi, T. (1382). Self-control in organization, Tehran: Tadbir publication.

18. Khalifeh, S., Eftekhar, A. (1377). Review job burnout in educational managers in Isfahan, Isfahan, Isfahan University, a master's thesis in Educational Management. 
19. Rahimi, S. (1379). Manager's burnout and about how it is, No. 109, Tadbir monthly magazine, Tehran.

20. Robbins, S. P. (1376). organization theory (translation Seyed Mehdi Alwan and Hassan Danaeefard), Tehran, Moj publishing, Saffar publishing.

21. Robbins, S. P. (1384). Management of Organizational Behavior (translator Farzad Omidvaryan), Tehran, Ketabe Mehraban institution publishing.

22. Robbins, S. P. (1386). Organizational Behavior, Volume III (translated by Ali Parsaeian and Seyyed Mohammad Arabi), Tehran, Cultural Research Bureau.

23. Teimouri Nasab, A. Rashidi, M. M. (1390). Job burnout syndrome of human resources in the oil industry, Tehran, Institute for International Energy Studies.

24. Zarei Matin, H. Seyedkalaly, N., Akhavan Anvari, M. (1391). Investigate the effect of job burnout on the employee's job implications, No. 9, the prospect of public administration, Tehran.

\section{Article history:}

- $\quad$ Received 15 October 2017

- $\quad$ Accepted 12 December 2017 